\title{
Review on Combined Methods for Sustainability Assessment and Development of Criteria-Set for a Systematization and Comparison Framework
}

\author{
Jan Bitter, Daniela Janssen, René Vossen, and Frank Hees
}

\begin{abstract}
In order to foster sustainable development in politics, society, technology (e.g. energy, mobility, industrial production) and other fields, it is essential to analyze and assess the sustainability of products, processes, strategies, organizations and actions regarding these fields. For that purpose, there are numerous approaches to sustainability assessment. A growing focus lies on multi-method or combined approaches. They offer the potential for integrated and holistic assessments regarding multiple sustainability dimensions, life cycle phases or input types. The variety of approaches impedes comparison and selection of the suitable approach for the respective assessment situation. This can lead to assessment errors and incredibility of results and thus, delay sustainable development. Systematization and comparison frameworks are needed to overcome this gap. This paper provides three main outcomes. Firstly, a review of existing multi-method sustainability assessment approaches gives insights into the status quo and the characteristics of existing approaches. Secondly, a review of frameworks for systemizing and comparing assessment approaches provides an overview of perspectives and criteria for such frameworks. Finally, considering characteristics of multi-method approaches and criteria from existing frameworks, a comprehensive criteria-set is developed. The criteria-set marks the starting point for the development of a holistic systematization and comparison framework in future works.
\end{abstract}

Index Terms-Method combination, multi-method approach, sustainability assessment, systematization and comparison framework.

\section{INTRODUCTION}

Sustainable development has emerged from an idealists' claim to a widely acknowledged, international goal, politically manifested within the 17 Sustainable Development Goals (SDGs) [1]. This development can be observed in diverse fields, such as politics, society, environmental issues, and technology - e.g. energy, mobility, and industrial production. While there are numerous descriptions and notions of sustainable development, one of the most common definitions is the United Nations' (UN), first formulated within the Brundtland-Report in 1987: "Sustainable development [...] meets the needs of the present without compromising the ability of future generations to meet their own needs." [2]. Sustainable development is considered as

Manuscript received February 5, 2018; revised June 29, 2018.

The authors are with the Cybernetics Lab IMA/ZLW \& IfU, RWTH Aachen University, Dennewartstrasse 27, 52068 Aachen, Germany (corresponding author: Jan Bitter; e-mail: jan.bitter@ima-zlw-ifu.rwth-aachen.de). the pathway to sustainability, thus differentiating both terms [3]. Further describing and interpreting the UN's definition, the commonly accepted notion of sustainability describes a holistic concept that tries to reconcile human activities with the carrying capacity and exhaustibility of the natural environment and human needs - today and in the future [1]. Based on this notion, there are three widely acknowledged dimensions (also: pillars) of sustainability: ecology, economy, and social issues [4], [5].

As sustainability describes a state, that ought to be reached by sustainable development, there are numerous approaches to analyze, measure and assess sustainability, more precisely the degree of achieving the state of sustainability [6]. The objective of these approaches is to provide decision makers with the necessary information and context required to support them in defining short- and long-term actions within the complex and multi-dimensional construct of sustainable development [6]-[8].

The multitude of existing approaches comprises both single-method-approaches and combined or multi-method-approaches. Especially a growing focus on integrated approaches - regarding multidimensionality, holistic life cycle or supply chain view, assessment elements, and quantitative and qualitative aspects - leads to a growing number of combined or multi-method approaches [9]-[12]. Taking into account the variety of approaches to sustainability assessment, there is broad agreement, that each single- or multi-method approach has its own advantages and disadvantages - especially regarding the respective assessment object, scope and objective [7], [13]-[15]. Existing works give overviews of prevalent approaches including the discussion of potentials and limits. However, there is a lack of structured systematizations of approaches as well as structured comparisons and respective comparison criteria beyond theoretical discussions of advantages and disadvantages [7], [9]. Such systematization and comparison frameworks support users of sustainability assessments, such as political, social or economic decision-makers, engineers, product and process designers, and others, in identifying and selecting the best suited approach, i.e. method set, for the respective assessment situation. Without a structured comparison and selection process, that is based on a solid theoretical framework, the resulting assessment may be erroneous and can be vulnerable towards criticism and doubts regarding its credibility [16]. Such insecurities, lack of knowledge, and potential vulnerability decelerate sustainable development. For a sound theoretical basis, comparison and systematization criteria are required. 
With a focus on combined multi-method approaches, this work aims to provide a systematic overview of existing approaches to sustainability assessment, in order to develop a criteria-set for a framework for systematization and method comparison based on prevalent characteristics of combined multi-method approaches and criteria from existing categorizing frameworks. In Section II, the state of the art of combined sustainability assessment methods is presented. In Section III, comparison criteria for a systematization and comparison framework for combined methods for sustainability assessment are developed. The framework development itself is not the focus of this work. After a discussion of results, conclusions are given in Section IV.

\section{COMBINED Methods FOR SustainABILITY ASSESSMENT}

\section{A. Sustainability Assessment}

There is - similar to the terms Sustainable Development and Sustainability - no "[...] universal consensus as to what sustainability assessment is and how it should be applied" [9]. A generic definition of the term refers to it as "a process that directs decision-making towards sustainability" [9], [10], [17]. As can be seen from a high number of approaches as well as a growing number of scientific articles regarding sustainability assessment [9], this definition can be interpreted in various ways. However, sustainability assessment - in whichever way it is implemented - is seen as a "key decision-making tool" [9] for many different scopes of application (e.g. products, processes, businesses, and organizations or politics - regional, national, and international) [7], [8], [18], [19].

Generally, sustainability assessments encompass various elements concerning different assessment process stages. The elements comprise stakeholder and indicator selection, data collection and pre-processing, assessment logic, representation of results, and derivation of measures. Different approaches focus on different elements, either on a single element or multiple stages, up to integrated approaches, considering all elements for the assessment [10]. Especially approaches, that include multiple stages, commonly consist of multiple methods. That is, because certain methods are only suitable for specific elements or stages of the assessment process [15], [20]. The focus of this work lies on multi-method sustainability assessment approaches, thus, it would go beyond the scope of this paper, to present and discuss all existing (single-) methods, that are used in sustainability assessments. However, from literature, three main method categories can be deduced: life cycle (LC) approaches, multi-criteria decision analysis (MCDA), and others.

LC approaches include (environmental) Life Cycle Assessment (LCA), (economic) Life Cycle Costing (LCC) and Social Life Cycle Assessment (S-LCA) [13]. All of these approaches have in common, that they consider the entire life cycle of products or the complete supply or value chain of organizations from raw material extraction over manufacturing and use to final disposal. Thus, they generally provide a holistic picture of arising environmental, economic or social impacts of the object under investigation [13].
However, the costs of data acquisition, consolidation, and processing are high [21]. LCA, LCC and S-LCA are all based on ISO 14040 and 14044, leading to a somewhat standardized assessment process, even though results may vary due to inaccuracy related to data availability and accuracy, assumptions as well as the set system boundaries [13].

MCDA approaches are generally used to explicitly evaluate multiple, possibly conflicting criteria in decision-making and thus, are suitable for complex problems, such as sustainability assessments [22]. There are well over 30 different MCDA methods, and many have already been applied in the context of sustainability assessment [22]. Examples of such MCDA methods include, but are not limited to: Analytical Hierarchy/Network Process (AHP/ ANP), Data Envelopment Analysis (DEA), Grey Relational Analysis (GRA), ELimination Et Choice Translating Reality (ELECTRE), Preference Ranking Organization METHod for Enrichment Evaluation (PROMETHEE), and Fuzzy Logic approaches [14].

Other methods used in the context of sustainability assessment, that cannot be assigned to either category include, but are not limited to modelling techniques, such as System Dynamics Modelling (SDM) and Agent Based Modelling (ABM), or methods related to artificial intelligence, e.g. Neural Networks (NN) [23]-[25]. These methods are usually used in combination with one or more of the abovementioned LC and/or MCDA methods, depending on the objective and scope of the sustainability assessment.

In the following section $\mathrm{B}$, several of the above-mentioned as well as further methods illustrated in the context of combined methods for sustainability assessment. Extensive descriptions and explanations of all mentioned (and unmentioned) methods used in the context of sustainability assessment can be found in the relevant literature (cf. section References).

\section{B. Review on Combined Methods}

The first step in developing systematization and comparison criteria is a review of existing multi-method approaches to sustainability assessment. Some methods within this review are used in several combinations; hence each method is described at the place of their first reference. Specific characteristics of respective methods in certain combinations are highlighted accordingly.

\section{1) Life cycle sustainability assessment}

The single LC approaches, especially (environmental) LCA, are popular methods used for sustainability assessment [13]. However, each method merely focusses on a single dimension of sustainability. In order to provide a holistic picture of sustainability, the author of [26] proposes a framework for combining LCA, LCC and S-LCA to a Life Cycle Sustainability Assessment (LCSA). He underlines the importance of an integrated assessment by interpreting the results of each LC approach next to each other, rather than simply summing them up [13], [26]. All three approaches follow a similar process, though there are some differences between the techniques, mainly related to the indicators and type of data being processed. Whilst in S-LCA qualitative and quantitative indicators can be processed, LCA and LCC 
completely rely on quantitative data. By possibly omitting relevant (qualitative) indicators, the assessment might be considered incomplete [11], [13], [26].

According to ISO 14040 and 14044, a LCA is carried out in four phases: 1) Definition of goal and scope, 2) inventory of resources use and emissions, 3) impact assessment (including optional normalization, aggregation and weighting of impact or damage categories), and 4) interpretation. As of today, there are extensive, widely acknowledged databases and software-tools that can be used for LCA.

Normalization of impact categories and/or indicators is used to facilitate the comparison of multiple inputs with different units. However, the application of normalization procedures for sustainability assessments is controversial, as it requires (subjective) threshold values, which can significantly influence the normalization and thus, assessment results [27].

In a LCC, the phases are comparable, though the focus lies on (monetary or monetized) costs and benefits along the LC of the assessment object: 1) Goal, scope and functional unit, 2) inventory costs, 3) aggregation of costs by cost categories, and 4) interpretation. Costs and benefits being included can be solely private costs/benefits, private costs plus external costs/benefits that are anticipated to be privatized (e.g. a tax on $\mathrm{CO}_{2}$ ) or all private and external costs/benefits. S-LCA similarly consists of four phases: 1) Goal and scope, including a collection of relevant stakeholders, 2) inventory of social/socio-economic impact categories, in consultation with the stakeholders, 3) impact assessment and 4) interpretation. The phases of S-LCA are not (yet) standardized. Especially the third phase strongly depends on the collected impact categories and indicators used to measure them. A current challenge for S-LCA is the qualitative nature of numerous relevant indicators and thus, difficulties in calculating reliable results [13], [26].

In order to reach a LCSA, there are generally two options for combining the three LC approaches. The first option is conducting three separate LC assessments with consistent, ideally identical system boundaries [26]. Thus, three results are interpreted separately and next to each other, providing a more holistic picture than stand-alone assessments. The second option is to conduct one combined definition of goal and scope (phase 1) and LC inventory (phase 2) for all sustainability dimensions together, followed by three separate impact assessments (phase 3) and either a joint or separate interpretation of results (phase 4) [13], [26]. Table I contains an overview of benefits and challenges of LCSA.

\section{2) LC approaches combined with MCDA approaches}

Several method combinations for sustainability assessment exist, that connect LC approaches - especially LCA as the most widespread technique - with MCDA approaches. Examples here are:

- LCA + AHP or ANP, e.g. [21], [28], [29],

- LCA + ELECTRE or PROMETHEE, e.g. [30], and

- LC + DEA, e.g. [31], [32].

While the LC approaches were described in the previous section, here, an overview of the listed MCDA approaches is given. The AHP is a method for quantifying subjective preferences based on pairwise comparison. It results in either weights for or a ranking of investigated alternatives [21], [33]. It consists of three parts: 1) structuring of a problem into a hierarchy consisting of a goal and subordinate features, 2) pairwise comparison between the elements at each level, and 3) calculation of priorities, weights or a ranking [28], [33]. Core element of the AHP is a pairwise comparison of elements. Here, the users evaluate for two criteria, which one is more important and how much more important on a scale from 1 (equally important) to 9 (extremely more important) [28], [33]. The results of pairwise comparisons are transferred into a matrix. The deduction of weights and/or a ranking is based on maximum eigenvalue and eigenvector [33].

TABLE I. BENEFITS AND CHALLENGES OF LCSA [13], [26]

\begin{tabular}{|c|c|}
\hline Bene & Cha \\
\hline $\begin{array}{l}\text { - Structuration of complex } \\
\text { sustainability issues } \\
\text { - Comprehensive picture of } \\
\text { positive/negative impacts in all } \\
\text { dimensions along the entire LC } \\
\text { - (Partly) standardized processes, } \\
\text { existing databases, software-tools } \\
\text { - Identification (and correction) of } \\
\text { trade-offs between different } \\
\text { sustainability dimensions } \\
\text { - Single techniques, especially } \\
\text { LCA, are popular, widely used and } \\
\text { acknowledged assessment } \\
\text { methods }\end{array}$ & $\begin{array}{l}\text { - (Partially) missing standardization } \\
\text { and/or clear processes for an } \\
\text { integrated, holistic assessment } \\
\text { - Difficulties in processing } \\
\text { qualitative data } \\
\text { - Lack of case studies for combined } \\
\text { LCSA } \\
\text { - Need for development of } \\
\text { streamlined approaches to reduce } \\
\text { costs for data acquisition and } \\
\text { processing } \\
\text { - No clear format for } \\
\text { communication and dissemination } \\
\text { of results }\end{array}$ \\
\hline
\end{tabular}

The ANP is the generalization of the AHP. It uses a network of criteria, rather than a strict hierarchy and thus, allows for the assessment of more complex real-world problems in which all considered elements can be related in any possible way. The general process of the ANP, however, is similar to the AHP as it also uses pairwise comparison, matrix, eigenvalue and eigenvector calculations [29].

In combinations of LC approaches and AHP/ANP, the latter are used to calculate weights for impact categories and/or indicators processed in the respective LC approach [21], [28], [29], [34]. These weights are then used during the impact assessment (phase 3 ) in order to account for differing relevance of impacts. The weighting of indicators - not only in LC approaches but in the context of sustainability assessment in general - is a controversial topic [13], [34]. On the one hand, weights have the potential of providing a more realistic picture of sustainability, on the other hand, weights are always subjective and can alter the results of an assessment considerably [34]. Table II contains benefits and challenges of the method combination LCA + AHP/ANP.

PROMETHEE is a MCDA method based on an outranking principle. It also uses pairwise comparison of alternatives to rank them regarding certain criteria. Preference functions are implemented to measure differences between two alternatives for any criteria in order to reach a weighted ranking based on the difference between inputs and outputs of the assessment object [14], [15]. ELECTRE, similarly, is an outranking method. It is based on two stages, the first being the construction of outranking relations and the second being the exploitation of these relations to rank the alternatives. The focus lies on dominance relations between these. For each criterion, a pairwise comparison of alternatives is conducted. Using concordance and discordance indexes and threshold 
values, graphs are created, from which the final ranking is deduced [15]. Both methods are suitable for decision problems with a finite number of alternatives and few (quantitative or qualitative) criteria. Depending on the application, the calculation process can be complex and thus costly [14], [15].

The combination of LCA and PROMETHEE or ELECTRE is used to compare and rank alternatives with regards to sustainability. The LCA first is used to assess several competing alternatives regarding their environmental impacts. From this assessment, no direct comparison of the alternatives is possible due to the variety of impact categories. Considering the alternatives and using the impact categories as criteria, the MCDA approaches are used to deduce a sustainability ranking in order to find the "best" or most sustainable alternative [30]. From such a ranking, merely a relative assessment is possible, i.e. one that relates alternatives to one-another. No absolute statement regarding the level of sustainability is possible.

TABLE II: BENEFITS AND CHALLENGES OF LC + MCDA APPROACHES [21], [28]-[32], [34]

\begin{tabular}{|c|c|c|}
\hline Combinations & Benefits & Challenges \\
\hline $\begin{array}{l}\text { LCA + } \\
\text { AHP/ANP }\end{array}$ & $\begin{array}{l}\text { - Weights from AHP/ } \\
\text { ANP aid interpretation } \\
\text { of LCA results } \\
\text { - Full LC view } \\
\text { - Expert/Stakeholder } \\
\text { inputs can be processed }\end{array}$ & $\begin{array}{l}\text { - Focus on environmental } \\
\text { aspects } \\
\text { - High cost for data } \\
\text { processing } \\
\text { - Purely subjective } \\
\text { assessment leads to } \\
\text { uncertainties }\end{array}$ \\
\hline $\begin{array}{l}\text { LCA + } \\
\text { ELECTRE/ } \\
\text { PROMETHEE }\end{array}$ & $\begin{array}{l}\text { - Ranking aids } \\
\text { comparison between } \\
\text { different alternatives } \\
\text { - Full LC view } \\
\text { - No compensation } \\
\text { between criteria or } \\
\text { dimensions }\end{array}$ & $\begin{array}{l}\text { - Relative assessment of } \\
\text { alternatives } \\
\text { - High cost for data } \\
\text { processing } \\
\text { - Complex mathematics }\end{array}$ \\
\hline $\mathrm{LC}+\mathrm{DEA}$ & $\begin{array}{l}\text { - LC for criteria selection } \\
\text { and quantification } \\
\text { - DEA aids interpretation } \\
\text { of LCA results through } \\
\text { scores and benchmarks }\end{array}$ & $\begin{array}{l}\text { - Costly data processing } \\
\text { - Complex optimization } \\
\text { models } \\
\text { - Relative assessment of } \\
\text { alternatives }\end{array}$ \\
\hline
\end{tabular}

DEA is a distance-to-target linear programming method for quantifying the relative productive efficiency of multiple similar entities that use (multiple) inputs and produce (multiple) outputs [31], [32], [35]. A function is developed, that is determined by the most efficient entity - i.e. a benchmark or "frontier" - with which a relative efficiency of alternatives can be calculated [35]. In the context of sustainability assessment, DEA is used to deduce weights and for benchmarking [31].

The authors of [31] provide an extensive overview of current applications of LC approaches in combination with DEA. Two general LC + DEA strategies are identified. Firstly, a five-step method "processes information on material and energy flows and socio-economic aspects to a sustainability outcome via the computation of consistent operational, socio-economic and environmental benchmarks associated with the optimized performance of the [decision making units]" [31]. Secondly, a three step procedure "addresses the direct, preliminary benchmarking of environmental, economic and social impacts of the [decision making units] under assessment" [31]. The combination of LC approaches and DEA creates some benefits but is also subject to limitations. These are presented in Table II.

\section{3) LC approaches combined with other approaches}

Examples for other approaches, that have been combined with LC approaches in the context of sustainability assessment are SDM and ABM. SDM is a method for modeling and understanding complex systems. A complex system is "a system in which large networks of components with no central control and simple rules of operation give rise to a complex collective behaviour, sophisticated information processing, and adaption via learning or evolution." [36]. Sustainability is a multidimensional construct incorporating interconnected, environmental, economic, and social aspects with a complex collective behavior. Therefore, it can also be viewed as a complex system, which has to be observed, analyzed, and modeled comprehensively [23].

SDM can be divided into qualitative and quantitative modeling [37]. Qualitative system models are mainly focused on identifying and visualizing closed feedback loops within the investigated systems. The interconnections and feedback loops are presented in so called causal loop or influence diagrams in order to identify and investigate possible (inter-) dependencies [37]. Quantitative system models are based on these causal loop diagrams but add flow charts using stocks, flows and auxiliary variables in order to calculate the complex system behavior. By adjusting the variables, different scenarios can be simulated and evaluated [37]. A popular application for SDM related to sustainability issues is the world model used for the work "Limits to Growth", one of the first studies concerned with the (environmental) impacts of mankind's economic activities [38].

The authors of [23] propose a combination of an integrated LCSA and SDM. The approach incorporates sub-models for environmental, economic and social aspects. Causal relationships between parameters and sub-models are included qualitatively and quantitatively. The combination of LCSA and SDM is realized by using LC impact categories and dynamically processing inputs and outputs within the SD model in order to investigate impacts over time. Calculations are - opposed to classical LC approaches - based on historical data and extend to forecasts for different scenarios. No formal LCA, LCC or SLCA as described above are conducted [23]. Benefits and challenges of the combination of LCSA and SDM are presented in Table III.

$\mathrm{ABM}$ is a modeling approach for the simulation of the individual and whole system behavior of (multiple) autonomous agents, which can be individual or collective entities. The agents act in an environment, communicate and interact with each other and have specific, built-in objectives, which they follow [39]. Thus, a complex system of agents can be simulated and the system behavior investigated over time.

The authors of [24] propose a combination of LCA and $\mathrm{ABM}$ for the use case of mobility policies. In this combination, (environmental) impacts of individual agents - i.e. car-users and the entire considered mobility system are calculated. The model simulates the LC phases from agents purchasing a car, using that car, selling and/or dismantling the car. The created data are used as inputs for a LC inventory, which is used for 
the final steps of a LCA, impact assessment and interpretation. In this study, different scenarios and respective LCA results are compared with each other in order to deduce policy implications [24]. Benefits and challenges of combining LCA with ABM are collected in Table III.

TABLE III: BENEFITS AND CHALLENGES OF LC + OTHER APPROACHES [23], [24]

\begin{tabular}{|c|c|c|}
\hline Combinations & Benefits & Challenges \\
\hline $\mathrm{LCSA}+\mathrm{SDM}$ & $\begin{array}{l}\text { Dynamic interactions } \\
\text { between indicators and } \\
\text { dimensions are included } \\
\text { - Scenarios can be tested } \\
\text { - Temporal aspects } \\
\text { (historical data/forecast) } \\
\text { - Graphical representation } \\
\text { of model and results } \\
\text { - Consideration of all } \\
\text { sustainability dimensions }\end{array}$ & $\begin{array}{l}\text { Does not follow } \\
\text { standardized LC process } \\
\text { - Model does not account } \\
\text { for uncertainties } \\
\text { - Elaborate process to build } \\
\text { the complex model }\end{array}$ \\
\hline $\mathrm{LCA}+\mathrm{ABM}$ & $\begin{array}{l}\text { - Consideration of complex } \\
\text { systems with multiple } \\
\text { agents } \\
\text { - Full LC perspective } \\
\text { - Scenarios can be tested } \\
\text { - High granularity and large } \\
\text { scale of data }\end{array}$ & $\begin{array}{l}\text { - Model does not account } \\
\text { for uncertainties } \\
\text { - Elaborate process to build } \\
\text { the complex model } \\
\text { - Results dependent on } \\
\text { assumptions and } \\
\text { data-availability } \\
\text { - High processing costs }\end{array}$ \\
\hline
\end{tabular}

TABLE IV: BENEFITS AND CHALLENGES OF COMBINED MCDA APPROACHES [20], [40]-[44]

\begin{tabular}{|c|c|c|}
\hline Combinations & Benefits & Challenges \\
\hline $\begin{array}{l}\text { AHP + Fuzzy } \\
\text { Logic }\end{array}$ & $\begin{array}{l}\text { Expert/Stakeholder inputs } \\
\text { can be processed } \\
\text { - Processing of } \\
\text { uncertainties } \\
\text { - Multiple types of inputs } \\
\text { (quantitative, qualitative, } \\
\text { linguistic) }\end{array}$ & $\begin{array}{l}\text { - Relative assessment of } \\
\text { alternatives } \\
\text { - No full LC perspective } \\
\text { - Complex mathematics } \\
\text { - Subjective (yet } \\
\text { objectified) weights }\end{array}$ \\
\hline $\begin{array}{l}\text { AHP/ ANP + } \\
\text { GRA }\end{array}$ & $\begin{array}{l}\text { - Assessment of complex } \\
\text { systems with multiple } \\
\text { input factors } \\
\text { - All sustainability } \\
\text { dimensions can be } \\
\text { included } \\
\text { - Inclusion of expert/ } \\
\text { stakeholder preferences }\end{array}$ & $\begin{array}{l}\text { - Complex mathematics, } \\
\text { costly application } \\
\text { - Non-transparent } \\
\text { calculations processes } \\
\text { - Relative assessment of } \\
\text { alternatives } \\
\text { - Subjective (objectified) } \\
\text { weights }\end{array}$ \\
\hline
\end{tabular}

\section{4) Combined MCDA approaches}

In recent years, MCDA approaches have grown increasingly popular in the context of sustainability assessment [22]. They are used as single methods, in combination with LC approaches, and in multi-method combinations of different MCDA methods. Examples for multi-MCDA-method approaches are:

- AHP + Fuzzy Logic (FAHP), e.g. [20], [40]-[42], and

- AHP or ANP + GRA, e.g. [43], [44].

A popular combination is that of the AHP (cf. section 2) and Fuzzy Logic, also called Fuzzy AHP or FAHP. Fuzzy Logic or Fuzzy Set Theory is based on the premise that objects can be attributed to more than one set, hence, their attribution is fuzzy. The approach is modeled after the human mind, which processes, rates, and summarizes qualitative information from numerical, categorical or linguistic data to make decisions and assessments [45]. Thus, crisp as well as fuzzy inputs can be processed to create crisp outputs. Sustainability issues - especially those concerning social aspects - cannot all be measured quantitatively. Qualitative or fuzzy - aspects of sustainability can be processed in a fuzzy system, to include them in the sustainability assessment [45].

Fuzzy Logic approaches are divided into several steps: 1) Normalization of indicators (optional), 2) definition of scales and membership functions, 3) definition of the rule base for aggregation, made up of simple "IF-THEN"-rules, 4) fuzzification, i.e. the attribution of inputs to membership functions, 5) fuzzy inference, i.e. the calculation of numerical membership grades based on the rule base, and 6) defuzzification, i.e. the calculation of output values from aggregated membership grades [45], [46]. A more detailed description of the process can for example be found in [45].

The combination of the AHP and Fuzzy Logic is realized by substituting the classical 9-point scale for pairwise comparison (cf. Section II) with fuzzy membership functions. Instead of valuing the relative importance of compared alternatives with a crisp number, users can give "fuzzy" scales, e.g. with a linguistic term, a range or a fuzzy number [47]. With fuzzy aggregation, preferences of multiple stakeholders can be used as inputs. The fuzzy inputs are transformed into crisp scales for the calculation of priority weights by employing defuzzification. Afterwards, fuzzy aggregation operators, i.e. fuzzy multiplication and addition operators are used to calculate the final fuzzy scores for comparison [41]. The FAHP is thus suitable to calculate weights and (sustainability) scores. There are several, somewhat varying, applications in the context of sustainability (e.g. [20], [40]-[42]). A common aspect of these use cases is that the application is elaborate and requires complex calculations [41]. Further challenges and benefits of the FAHP are presented in Table IV.

Another combination of two MCDA approaches is the one of AHP or ANP and GRA. The principle of GRA is based on the concept that the ideal alternative has the highest values for all considered criteria and the least ideal alternative has the lowest values. Thus, the "best" alternative has the shortest (geometrical) distance from the ideal solution and the longest distance from the least ideal solution [15]. The method is used for aggregation. Inputs are processed via the calculation of grey relational degrees (GRD), which reflect the distance relationships between the considered alternative and the ideal solution. The GRD is equal to the weighted sum of its grey relational coefficients (GRC) [15]. The alternative with the highest GRD is closest to the ideal and furthest from the least ideal solution. GRA is suitable for problems under uncertainty [15], [20].

The combination of AHP or ANP with GRA is realized by calculating GRC to determine the order of priority for multiple indices, AHP or ANP to calculate the weights of these indices and calculating GRD from GRC and weights in order to find the alternative with the highest value [43], [44]. Benefits and challenges of the method combination of AHP or ANP with GRA in the context of sustainability assessment are presented in Table IV.

\section{5) MCDA combined with other approaches}

Besides combining MCDA approaches with each other, there are some examples for the combination of MCDA approaches with non-categorized approaches. Examples for 
the context of sustainability assessment are:

- Fuzzy Logic + NN (Neuro-Fuzzy Logic), e.g. [25], and

- Fuzzy Logic Approach for Sustainability Assessment based on the Integrative Sustainability Triangle (Fuzzy-IST), e.g. [46].

$\mathrm{NN}$ are computational models consisting of nodes and connecting links. Their structure emulates the neural system of a brain, where the nodes are neurons and the links are synapses, that transmit signals between neurons. NN are capable of learning [48]. The author of [48] defines a neural network as: "[...] a massively parallel distributed processor made up of simple processing units that has a natural propensity for storing experiential knowledge and making it available for use. It resembles the brain in two respects:

1) Knowledge is acquired by the network from its environment through a learning process.

2) Interneuron connection strengths, known as synaptic weights, are used to store the acquired knowledge." [48]

The combination of NN and Fuzzy Logic is realized by using the latter for a comparative assessment of different options in order to deduce (relative) priority weights. These weights are then used as inputs for neuron computations in which output (assessment) values are generated that can be used for decision making [25]. Benefits and challenges of the Neuro-Fuzzy Logic approach to sustainability assessment are presented in Table V.

Another multi-method approach to sustainability assessment is the Fuzzy Logic Approach for Sustainability Assessment based on the Integrative Sustainability Triangle (Fuzzy-IST) proposed by the authors of [46]. The approach is a combination of Fuzzy Logic and an approach to systemizing and visualizing sustainability dimensions - the Integrative Sustainability Triangle (IST) [46]. The IST, proposed by the authors of [4], is an extension of the "classical" sustainability triangle, in which the corners represent the three dimensions ecology, economy, and social issues and the edges embody continuous intersection between two dimensions [5]. The IST adds discrete fields inside the triangle and allows for a classification of elements, such as indicators or fields of action in and between all three dimensions and thus, a comprehensive systemization of sustainability [46]. The IST can also be used as a means of visualization of sustainability elements, interdependencies between elements and dimensions, as well as for assessment results [4], [46].

The combination of Fuzzy Logic and IST is realized by first using the latter for systemizing sustainability indicators. Based on this, the indicators are processed within a fuzzy system following the steps as described above (cf. section 4). Finally, the results of the calculations are presented in a color-coded IST, in which, for each discrete field of the IST i.e. sustainability dimension or intersection of two or all three dimensions - the sustainability values are visualized as crisp numbers and via an eight-shade color-code. The shades go from red (low values) over yellow (medium values) to green (high values) [46]. In the current version of the IST, the indicators are weighted equally. However, the application of the AHP by an expert group to deduce (subjective) weights, as an additional method, is possible [46]. Benefits and challenges of the Fuzzy-IST are presented in Table V.
TABLE V: BENEFITS AND CHALLENGES OF MCDA + OTHER APPROACHES [25], [46]

\begin{tabular}{|c|c|c|}
\hline Combinations & Benefits & Challenges \\
\hline $\begin{array}{l}\text { Fuzzy Logic + } \\
\text { NN }\end{array}$ & $\begin{array}{l}\text { - Processing of large } \\
\text { amounts of data } \\
\text { - Complex systems } \\
\text { - Learning ability } \\
\text { - Processing of fuzzy } \\
\text { inputs }\end{array}$ & $\begin{array}{l}\text { - Relative assessment of } \\
\text { alternatives } \\
\text { - Complex mathematics } \\
\text { - Non-transparent } \\
\text { procedures }\end{array}$ \\
\hline Fuzzy-IST & $\begin{array}{l}\text { - Integrated assessment of } \\
\text { sustainability dimensions } \\
\text { and LC phases } \\
\text { - Visualization of results } \\
\text { - Qualitative and } \\
\text { quantitative inputs } \\
\text { - Processing of } \\
\text { uncertainties } \\
\text { - Processing of expert } \\
\text { - knowledge } \\
\text { - Absolute assessment }\end{array}$ & $\begin{array}{l}\text { - Elaborate procedure with } \\
\text { high cost for data } \\
\text { acquisition and } \\
\text { processing } \\
\text { - Subjective (objectified) } \\
\text { rule base and weights } \\
\text { - Few case studies } \\
\text { - No software support }\end{array}$ \\
\hline
\end{tabular}

Based on the review of multi-method approaches to sustainability assessment as well as an analysis of existing frameworks and categorizations, comparison criteria for the development of a systematization and comparison framework for sustainability assessment method combinations are identified as presented in the following Section III.

\section{CRITERIA FOR DEVELOPING A SYSTEMATIZATION AND COMPARISON FRAMEWORK}

\section{A. Systematization and Comparison Criteria from Existing Frameworks and Categorizations}

In the past two decades, several authors proposed frameworks for structuring, evaluating and/or comparing approaches in the context of sustainability assessment or, at least, related fields (e.g. environmental assessment).

The authors of [49] propose a framework for conceptual and analytical approaches used in environmental management. The framework includes eleven structuring aspects: nature of approach, type of decision-maker, overall purpose, object analyzed, perspective, investigated dimensions, character of the approach, basis for comparison, system boundaries, type of data (input and output data), and evaluation of results/interpretation [49]. These aspects are further detailed by categories. An example is the aspect perspective being divided into prospective and retrospective [49]. While this framework does not refer to sustainability assessment directly, it represents the - at the time of publication - prevailing, eco-centric view on sustainability.

Building on this early framework, the authors of [8], narrow down the number of categorizing factors for their own framework to three: temporal characteristics (descriptive or forecasting), focus (e.g. at product or at policy level), and integration of nature-society systems, i.e. of the sustainability dimensions [8]. Based on these factors, the framework categorizes tools for sustainability assessment within the following areas: indicators and indices (non-integrated and integrated), product-related assessment (i.e. those based on a LC perspective), as well as integrated assessment and monetary valuation [8].

In [16], the authors propose five features, to be used as a 
means to systemize the selection of the appropriate tool for sustainability assessment: integration of dimensions, time focus (descriptive or predictive), inter- and intra-generational equity, as well as handling of uncertainties and participation [16]. While [16] refers to the selection of tools, the authors of [9] propose another framework for comparison of sustainability assessment processes. It contains six comparison criteria: procedural, substantive, transactive, normative effectiveness, pluralism, as well as knowledge and learning [9]. The comparison framework relies on answering questions allocated to each criterion [9].

From the state-of-the-art reviews [50] and [7], that both analyze, discuss, and evaluate different approaches to sustainability assessment, relevant comparison criteria are: (generic) applicability, time-frame of application, application focus (e.g. factory level), incorporation of sustainability dimensions, (LC) boundaries of analysis, and method of analysis - i.e. quantitative or qualitative [7], [50]. While [7] focuses on approaches to assess the product and/or process level, [50] considers tools for factory assessment.

The authors of [51] perform a review of several methods for sustainability assessment and categorize and evaluate them regarding the steps of the assessment process, more precisely, which approaches are used in which step. The seven steps are: selection of assessment criteria (which criteria and how are they selected), gathering information and data (from primary or secondary sources, expert knowledge or others), obtaining sustainability indicators (with quantitative or qualitative methods), normalization of indicators, weighting criteria (objective or subjective approaches), comparison and selection of best alternative (i.e. which methods are used for calculating sustainability values), and sensitivity analysis (if and in which step it is used) [51]. While this review covers numerous approaches, its main purpose is to analyze the distributions of different methods throughout the current literature without a direct comparison.

In [22], the authors define ten comparison criteria for MCDA methods that are used in the context of sustainability assessments. These are: use of qualitative and quantitative information, LC perspective, weights typology, threshold values, compensation degree (between sustainability dimensions), uncertainty treatment/sensitivity analysis, robustness, software support and graphical representation, ease of use, and a learning dimension [22]. Based on these criteria, a comparison between different methods is conducted which results in a qualitative assessment of criteria fulfillment (on the scale good-intermediate-poor). The comparison is based on literature sources rather than the authors' opinion [22].

The presented frameworks and categorizations have different foci and objectives. None of the frameworks directly addresses multi-method approaches. However, there are overlaps regarding structuring aspects. From the analysis of these recurring elements and existing multi-method combinations for sustainability assessment (cf. section II), comparison criteria are deduced and collected in the following section $\mathrm{B}$.

\section{B. Comparison Criteria for Framework Development}

For the development of a comprehensive framework for systematization and comparison of multi-method approaches to sustainability assessment, comparison criteria are needed. In order to deduce these criteria, within this work, a structured approach is followed, that consists of three steps, each divided into two or three sub-steps. These are:

1) Review and analysis of existing multi-method approaches

- Initial categorization based on analyzing method descriptions (procedure, application, scope etc.)

- Collection and analysis of specific characteristics (benefits and challenges) as discussed in the literature

- Review of descriptions and specific characteristics to summarize and cluster similarities and differences

2) Review and analysis of existing frameworks

- Collection of criteria used in frameworks for systematization and comparison of approaches to sustainability assessment and related fields

- Clustering and summarizing criteria based on similarities in descriptions

3) Development of criteria-set from previous analyses

- Systematic comparison of clustered characteristics of multi-method approaches (step 1) and criteria from existing frameworks (step 2)

- Consolidation of final criteria-set comprising criterion name, description and/or elaboration and sources

Following this structured approach, a total of 20 criteria are deduced, which represent a consolidation of prevalent characteristics of multi-method approaches to sustainability assessment and criteria from existing frameworks. The final criteria-set is described in the following:

- Category of approach - i.e. LC, MCDA or other approaches as well as further subcategories (e.g. outranking, distance-to-target etc.) (cf. section II)

- Focused sustainability dimension - i.e. ecology, economy and social issues or approaches, considering intersections of two or all three dimensions [7], [8], [13], [16], [20], [23], [26], [31], [40]-[44], [46], [49]

- Focused LC stages and/or parts of the supply chain up to holistic approaches, integrating the entire LC/supply chain [7], [8], [13], [19], [21], [22], [26], [28]-[32], [46], [52]

- Included assessment-process elements - i.e. the focus on different process stages [10], [15], [20], [49]

- Type of input data - i.e. quantitative or qualitative data, numerical or linguistic inputs [7], [13]-[15], [19], [20], [22], [23], [26], [27], [40]-[42], [46], [49], [51]

- Scope of application or generalization level - i.e. the targeted range of applications for different objects of investigation [7], [8], [18], [19], [50], [52]

- Level of integration - i.e. are different aspects (e.g. sustainability dimensions/LC phases) assessed integrated or side-by-side [8], [13], [16], [19], [26], [46], [52]

- Standardization and transparency - i.e. level of comprehensibility and repeatability of assessment processes and results [13], [25], [26], [43], [44]

- Data sources - i.e. primary or secondary data, expert knowledge, simulations, analogies or others [21], [25], [28], [29], [46], [51]

- Weighting and/or normalization of indicators or criteria i.e. if and which type of weighting and/or normalization is incorporated [19]-[21], [25], [27]-[32], [40]-[42] 
- Output type - i.e. absolute or relative measure(s), single or multiple numerical output(s), graphical representation [8], [19]-[21], [28]-[30], [40]-[44], [46], [49]

- Dynamism - i.e. is the assessment based on a static state ("snapshot") or on a dynamic model, that considers interdependencies [22]-[25]

- Temporal characteristics - i.e. retrospective/descriptive or prospective/predictive evaluation [8], [16], [23]-[25], [49]

- Treatment of uncertainties - i.e. if uncertainties are ignored, deliberately incorporated, minimized etc. [16], [20], [22]-[24], [40]-[42], [46]

- Ease of use or applicability - i.e. the cost (time, money, effort) for conducting the assessment and accessibility of assessment procedures and principles [13], [20], [23]-[26], [40]-[42], [46], [50], [52]

- Participation and democracy - i.e. how stakeholders and/or experts are involved in the assessment [9], [16], [20], [21], [28], [29], [40]-[44], [46], [51]

- Accuracy or level of detail - i.e. precision and reliability of the assessment from rough estimate or general tendency to exact output [13], [24], [26], [46], [52]

TABLE VI: EXAMPLE OF STRUCTURED METHOD DESCRIPTION BASED ON DEVELOPED CRITERIA-SET FOR FUZZY-IST [46]

\begin{tabular}{|c|c|}
\hline Criterion & Description \\
\hline Category of approach & MCDA + other \\
\hline Focused sustainability dimension & All dimensions and intersections \\
\hline $\begin{array}{l}\text { Focused LC stages and/or parts of the } \\
\text { supply chain }\end{array}$ & All LC stages \\
\hline Included assessment-process elements & $\begin{array}{l}\text { Indicator selection, data collection } \\
\text { and pre-processing, assessment } \\
\text { logic, representation of results }\end{array}$ \\
\hline Type of input data & Quantitative and qualitative \\
\hline $\begin{array}{l}\text { Scope of application or generalization } \\
\text { level }\end{array}$ & $\begin{array}{l}\text { Currently: energy technologies, } \\
\text { wider scope possible }\end{array}$ \\
\hline Level of integration & $\begin{array}{l}\text { Separated and integrated } \\
\text { assessment of sustainability } \\
\text { dimensions and LC phases }\end{array}$ \\
\hline Standardization and transparency & $\begin{array}{l}\text { Not standardized, clear process } \\
\text { steps, non-transparent rule base }\end{array}$ \\
\hline Data sources & Primary and secondary data \\
\hline $\begin{array}{l}\text { Weighting and/or normalization of } \\
\text { indicators or criteria }\end{array}$ & $\begin{array}{l}\text { Equal weighting, normalization } \\
\text { scheme applied }\end{array}$ \\
\hline Output type & $\begin{array}{l}\text { Multiple numerical indices for } \\
\text { sustainability dimensions and } \\
\text { overall sustainability, color-coded } \\
\text { visualization of numerical outputs }\end{array}$ \\
\hline Dynamism & Static model \\
\hline Temporal characteristics & Retro- or prospective \\
\hline Treatment of uncertainties & Incorporated via fuzzy approach \\
\hline Ease of use or applicability & $\begin{array}{l}\text { Depends on design of } \\
\text { situation-specific assessment } \\
\text { model (indicators, rule base etc.) }\end{array}$ \\
\hline Participation and democracy & $\begin{array}{l}\text { Expert participation, no } \\
\text { stakeholders directly involved }\end{array}$ \\
\hline Accuracy or level of detail & $\begin{array}{l}\text { Depends on design of } \\
\text { situation-specific assessment } \\
\text { model (indicators, rule base etc.) }\end{array}$ \\
\hline $\begin{array}{l}\text { Substitutability of indicators/ } \\
\text { dimensions or handling of trade-offs }\end{array}$ & Depends on fuzzy rule base \\
\hline User(s) and/or target group(s) & Decision-makers, analysists \\
\hline Number of combined methods & Two (in base method) \\
\hline
\end{tabular}

- Substitutability of indicators/dimensions or handling of trade-offs - i.e. the degree to which indicators or sustainability dimensions balance out negative/positive effects of other indicators/dimensions [9], [22], [46]

- User(s) and/or target group(s) - e.g. decision makers, analysts, private individuals [9], [49], [52]

- Number of combined methods (cf. section II)

Existing (cf. section II) and potential, new method combinations for sustainability assessment can be described and thus, systemized using the resulting criteria-set. That way, approaches are made comparable and a structured selection process is facilitated. As an example, Table VI contains a structured (qualitative) description of the Fuzzy-IST based on the developed criteria-set.

\section{DISCUSSION}

The review of multi-method approaches to sustainability assessment (cf. section II) gives an overview of existing method combinations and their benefits and challenges. None of the presented approaches has solely positive or negative attributes, which shows, that there is - and probably cannot be - any agreement on the "best" approach. Each approach is developed and tested for a limited number of fields of application, thus not every approach is suitable for every assessment situation. However, combined approaches - as they bring together characteristics of the single methods offer a high potential for overcoming shortcomings of single method approaches (cf. Tables I-V). This relates to aspects like sustainability dimensions or assessment process stages being considered, participation of stakeholders in the assessment process or handling uncertainties regarding inand outputs, to name but a few.

Furthermore, the review shows that there is already a great variety of such method combinations, which will most likely increase further for two main reasons. Firstly, there are still combinations, that have not yet been investigated and which - by simply considering the positive features of the single methods - might be promising. Secondly, constantly more existing or completely new (single) methods are tested in the context of sustainability assessment, thus the potential for new method combinations grows even further. This growth adds to the difficulty, users of sustainability assessments encounter when comparing and selecting the appropriate approach for the respective assessment situation.

The great number and variety of approaches - of which this work only shows an exemplary excerpt - naturally leads to numerous different characteristics of multi-method approaches. Some characteristics are recurring, such as the focus on at least one sustainability dimension (cf. section III). Some are less common, such as the ability to process interdependencies of indicators and/or sustainability dimensions within dynamic assessment models (cf. section III). This multitude of characteristics underlines the importance of frameworks that support users of sustainability assessments in comparing and selecting the appropriate approach for the respective situation. More specifically, frameworks, that go further than generic rules that guide the selection process [16]. 
Existing frameworks focus on different aspects, such as one specific sustainability dimension [49], single or multiple categories of approaches [8], [22], tool selection or comparison based on overarching guidelines or simple questions [9], [16], specific fields of application [7], [50] or different steps of the assessment process [51]. The review of these frameworks results in an overview of how - from different perspectives - systematizations of sustainability assessment approaches can be reached and which criteria are used in the process.

In this work, criteria are identified, which are needed for the development of a comprehensive framework for comparison and systematization of combined methods for sustainability assessment. The resulting 20 criteria extend the criteria being used in existing frameworks as they bring together different aspects and perspectives and explicitly consider the characteristics of existing multi-method approaches. The list of criteria is based on an extensive analysis of literature connected to the subjects of this work. However, in order to investigate the applicability and validity of the criteria-set, it needs to actually be transferred into a comprehensive framework and tested by categorizing multi-method approaches within this framework. The exemplary structured method description of the Fuzzy-IST (cf. Table VI) based on the criteria-set shows its general applicability. However, the description is merely qualitative and consistent, somewhat standardized criteria values are needed for a comprehensive comparison of different approaches.

\section{CONCLUSION}

In conclusion, the results of this work provide a basis for further research activities. The review of existing combined methods for sustainability assessment provides insights into the status quo as well as benefits and challenges. However, for a comprehensive comparison of different approaches, a finalized framework is necessary. For this, the logical next steps are transferring the criteria into a comprehensive structure in which, for example categories or clusters of criteria could further add to the systematization. Representing the criteria-set and additional structural elements in a matrix format helps visualizing the systemizing approach. Also, for each criterion, consistent (linguistic or numerical) scales need to be developed, that could facilitate the classification within the framework and comparison between approaches. Such scales could be, for example, yes or no (binary scale), badmedium - good as a linguistic scale or on an interval, e.g. $[0,1]$, as degree of fulfillment. Next, multi-method approaches need to be classified and compared within the framework in order to validate its usability. The development and validation of such a framework is not part of this work, as it would go beyond its scope. However, the identified criteria-set extends existing systematization and comparison criteria and marks a starting point for the framework development.

\section{REFERENCES}

[1] United Nations. (2016). Sustainable development goals - United Nations. United Nations Sustainable Development. [Online]. Available:

http://www.un.org/sustainabledevelopment/sustainable-developmentgoals/

[2] G. Brundtland et al., Our Common Future, Oxford University Press, USA, 1987, ch. 2, p. 41.

[3] D. Reid, Sustainable Development: An Introductory Guide, Routledge, 2013, p. xiv.

[4] A. Kleine and M. Hauff, "Sustainability-driven implementation of corporate social responsibility: Application of the integrative sustainability triangle," J. Bus. Ethics, vol. 85, no. S3, pp. 517-533, 2009.

[5] R. B. Gibson, "Beyond the pillars: Sustainability assessment as a framework for effective integration of social, economic and ecological considerations in significant decision-making," J. Environ. Assess. Policy Manag., vol. 8, no. 03, pp. 259-280, 2006.

[6] J. Bebbington, J. Brown, and B. Frame, "Accounting technologies and sustainability assessment models," Ecol. Econ., vol. 61, no. 2-3, pp. 224-236, Mar. 2007.

[7] P. Ghadimi, N. M. Yusof, M. Z. M. Saman, and M. Asadi, "Methodologies for measuring sustainability of product/process: A review," Pertanika J. Sci. Technol., vol. 21, pp. 303-326, 2013.

[8] B. Ness, E. Urbel-Piirsalu, S. Anderberg, and L. Olsson, "Categorising tools for sustainability assessment," Ecol. Econ., vol. 60, no. 3, pp. 498-508, 2007.

[9] A. Bond, A. Morrison-Saunders, and J. Pope, "Sustainability assessment: The state of the art," Impact Assess. Proj. Apprais., vol. 30, no. 1, pp. 53-62, 2012.

[10] T. Hacking and P. Guthrie, "A framework for clarifying the meaning of triple bottom-line, integrated, and sustainability assessment," Environ. Impact Assess. Rev., vol. 28, no. 2-3, pp. 73-89, Feb. 2008.

[11] T. Hák, B. Moldan, and A. L. Dahl, Sustainability Indicators: A Scientific Assessment, Island Press, 2012.

[12] T. Waas, J. Hugé, T. Block, T. Wright, F. Benitez-Capistros, and A. Verbruggen, "Sustainability assessment and indicators: Tools in a decision-making strategy for sustainable development," Sustainability, vol. 6, no. 9, pp. 5512-5534, Aug. 2014.

[13] S. Valdivia, G. Sonnemann, C. M. L. Ugaya, and J. Hildenbrand, Towards a Life Cycle Sustainability Assessment - Making Informed Choices on Products, Paris: UNEP/SETAC Life Cycle Initiative, 2011.

[14] R. Abu-Taha, "Multi-criteria applications in renewable energy analysis: A literature review," Technol. Manag. Energy Smart World PICMET 2011, pp. 1-8, 2011.

[15] J.-J. Wang, Y.-Y. Jing, C.-F. Zhang, and J.-H. Zhao, "Review on multi-criteria decision analysis aid in sustainable energy decision-making," Renew. Sustain. Energy Rev., vol. 13, no. 9, pp. 2263-2278, 2009.

[16] A. Gasparatos and A. Scolobig, "Choosing the most appropriate sustainability assessment tool," Ecol. Econ., vol. 80, pp. 1-7, 2012.

[17] A. J. Bond and A. Morrison-Saunders, "Re-evaluating Sustainability Assessment: Aligning the vision and the practice," Environ. Impact Assess. Rev., vol. 31, no. 1, pp. 1-7, Jan. 2011.

[18] R. K. Singh, H. R. Murty, S. K. Gupta, and A. K. Dikshit, "An overview of sustainability assessment methodologies," Ecol. Indic., vol. 9, no. 2, pp. 189-212, Mar. 2009.

[19] S. G. Azevedo, R. Godina, and J. C. O. Matias, "Proposal of a sustainable circular index for manufacturing companies," Resources, vol. 6, no. 4, p. 63, Nov. 2017.

[20] G. Liu, "Development of a general sustainability indicator for renewable energy systems: A review," Renew. Sustain. Energy Rev., vol. 31, pp. 611-621, 2014.

[21] B. G. Hermann, C. Kroeze, and W. Jawjit, "Assessing environmental performance by combining life cycle assessment, multi-criteria analysis and environmental performance indicators," J. Clean. Prod., vol. 15 , no. 18, pp. 1787-1796, Dec. 2007.

[22] M. Cinelli, S. R. Coles, and K. Kirwan, "Analysis of the potentials of multi criteria decision analysis methods to conduct sustainability assessment," Ecol. Indic., vol. 46, pp. 138-148, Nov. 2014.

[23] N. C. Onat, M. Kucukvar, O. Tatari, and G. Egilmez, "Integration of system dynamics approach toward deepening and broadening the life cycle sustainability assessment framework: A case for electric vehicles," Int. J. Life Cycle Assess., Feb. 2016.

[24] Q. Florent and B. Enrico, "Combining agent-based modeling and life cycle assessment for the evaluation of mobility policies," Environ. Sci. Technol., vol. 49, no. 3, pp. 1744-1751, Feb. 2015. 
[25] R. Mamlook, B. A. Akash, and M. S. Mohsen, “A neuro-fuzzy program approach for evaluating electric power generation systems," Energy, vol. 26, no. 6, pp. 619-632, 2001.

[26] W. Kloepffer, "Life cycle sustainability assessment of products: (With comments by Helias A. Udo de Haes, p. 95)," Int. J. Life Cycle Assess., vol. 13, no. 2, pp. 89-95, Mar. 2008.

[27] N. L. Pollesch and V. H. Dale, "Normalization in sustainability assessment: Methods and implications," Ecol. Econ., vol. 130, pp. 195-208, Oct. 2016.

[28] S. Väisänen, M. Mikkilä, J. Havukainen, L. Sokka, M. Luoranen, and M. Horttanainen, "Using a multi-method approach for decision-making about a sustainable local distributed energy system: A case study from Finland," J. Clean. Prod., vol. 137, pp. 1330-1338, Nov. 2016

[29] F. Felice, F. Campagiorni, and A. Petrillo, "Economic and environmental evaluation via an integrated method based on LCA and MCDA," Procedia - Soc. Behav. Sci., vol. 99, pp. 1-10, Nov. 2013.

[30] I. Boufateh, A. Perwuelz, B. Rabenasolo, and A. M. J. Desodt, "Multiple criteria decision-making for environmental impacts optimisation," Int. J. Bus. Perform. Supply Chain Model, vol. 3, no. 1, p. $28,2011$.

[31] M. Martín-Gamboa, D. Iribarren, D. García-Gusano, and J. Dufour, “A review of life-cycle approaches coupled with data envelopment analysis within multi-criteria decision analysis for sustainability assessment of energy systems," J. Clean. Prod., vol. 150, supplement C, pp. 164-174, May 2017.

[32] I. Vázquez-Rowe and D. Iribarren, "Review of life-cycle approaches coupled with data envelopment analysis: Launching the CFP," The Scientific World Journal, 2015.

[33] T. L. Saaty, "The analytic hierarchy process: planning, priority setting, resources allocation," N. Y. McGraw, 1980.

[34] T. Myllyviita, A. Holma, R. Antikainen, K. Lähtinen, and P. Leskinen, "Assessing environmental impacts of biomass production chains application of life cycle assessment (LCA) and multi-criteria decision analysis (MCDA)," J. Clean. Prod., vol. 29-30, pp. 238-245, Jul. 2012.

[35] W. W. Cooper, L. M. Seiford, and J. Zhu, "Data envelopment analysis," Handbook on Data Envelopment Analysis, Springer, Boston, MA, 2004, pp. 1-39.

[36] M. Mitchell, Complexity: A Guided Tour, Oxford University Press, 2009.

[37] R. G. Coyle, System Dynamics Modelling: A Practical Approach, CRC Press, 1996.

[38] D. H. Meadows, D. L. Meadows, J. Randers, and W. W. Behrens, "The limits to growth," Club of Rome, New York, 1972.

[39] D. Helbing, "Agent-based modeling," Social Self-Organization, Springer, Berlin, Heidelberg, 2012, pp. 25-70.

[40] P. Ghadimi, A. H. Azadnia, N. Mohd Yusof, and M. Z. Mat Saman, “A weighted fuzzy approach for product sustainability assessment: a case study in automotive industry," J. Clean. Prod., vol. 33, pp. 10-21, Sep. 2012.

[41] C. Kahraman, İ. Kaya, and S. Cebi, "A comparative analysis for multiattribute selection among renewable energy alternatives using fuzzy axiomatic design and fuzzy analytic hierarchy process," Energy, vol. 34, no. 10, pp. 1603-1616, Oct. 2009.

[42] G. Liu, M. G. Rasul, M. T. O. Amanullah, and M. M. K. Khan, "Sustainability indicator of renewable energy system based on fuzzy multi-criteria decision making methods," Adv. Mater. Res., vol. 361-363, pp. 1263-1273, Oct. 2011.
[43] G. Xu, Y. Yang, S. Lu, L. Li, and X. Song, "Comprehensive evaluation of coal-fired power plants based on grey relational analysis and analytic hierarchy process," Energy Policy, vol. 39, no. 5, pp. 2343-2351, May 2011.

[44] S. H. Hashemi, A. Karimi, and M. Tavana, "An integrated green supplier selection approach with analytic network process and improved Grey relational analysis," Int. J. Prod. Econ., vol. 159, pp 178-191, Jan. 2015.

[45] Y. A. Phillis and V. S. Kouikoglou, Fuzzy Measurement of Sustainability, NY: Nova Science Publishers, 2009.

[46] J. Bitter, S. Printz, K. Lahl, R. Vossen, and S. Jeschke, "Approach to sustainability assessment of renewable energy technologies combining fuzzy logic with the integrative sustainability triangle," Int. J. Sustain. Energy Dev., vol. 5, no. 1, pp. 252-262, 2016.

[47] J. Zeng, M. An, and N. J. Smith, “Application of a fuzzy based decision making methodology to construction project risk assessment," Int. J. Proj. Manag., vol. 25, no. 6, pp. 589-600, Aug. 2007.

[48] S. S. Haykin, S. S. Haykin, S. S. Haykin, and S. S. Haykin, Neural Networks and Learning Machines, vol. 3,Pearson Upper Saddle River, NJ, USA, 2009.

[49] H. Baumann and S. J. Cowell, "An evaluative framework for conceptual and analytical approaches used in environmental management," Greener Manag. Int., vol. 26, pp. 109-122, 1999.

[50] D. Chen, T. Schudeleit, G. Posselt, and S. Thiede, "A state-of-the-art review and evaluation of tools for factory sustainability assessment," Procedia CIRP, vol. 9, pp. 85-90, 2013.

[51] V. Ibáñez-Forés, M. D. Bovea, and V. Pérez-Belis, "A holistic review of applied methodologies for assessing and selecting the optimal technological alternative from a sustainability perspective," J. Clean Prod., vol. 70, supplement C, pp. 259-281, May 2014.

[52] K. S. Sangwan, V. Bhakar, and A. k Digalwar, "Sustainability assessment in manufacturing organizations - development of assessment models," Benchmarking Int. J., 2018.

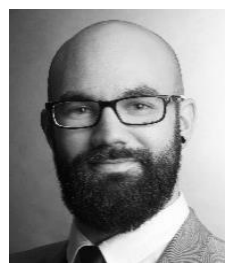

Jan Bitter was born in Achim, Germany in 1989. He obtained a master of science in business administration and mechanical engineering at RWTH Aachen University in Aachen, Germany in 2015. In 2014, he completed a semester abroad at the School of Aerospace, Mechanical \& Manufacturing Engineering at RMIT University in Melbourne, Australia. Before that, he finished his bachelor's degree in business administration and mechanical engineering at RWTH Aachen University in 2013. During his academic career, his main fields of study were textile \& composite engineering and sustainability sciences.

Since 2016 he is working as a scientific researcher and doctoral candidate at the Cybernetics Lab IMA/ZLW \& IfU at RWTH Aachen University in the research group Economic and Social Cybernetics. In this position, he already published two conference papers and two journal articles on the development and verification of the "Fuzzy Logic Approach for Sustainability Assessment Based on the Integrative Sustainability Triangle" (Fuzzy-IST). During his studies (2009-2015) he completed an internship at Daimler AG and worked as a student assistant at different institutes of RWTH Aachen University. His current fields of research are sustainability assessments and respective approaches. Mr. Bitter is a member of the German Association of Engineers (VDI). 